\title{
Production of Designer Mabe Pearls in the Black-lipped Pearl Oyster, Pinctada margaritifera, and the Winged Pearl Oyster, Pteria penguin, from Andaman and Nicobar Islands, India
}

\author{
V. KRIPA \\ Research Center of Central Marine Fisheries Research Institute, West Hill, \\ Calicut 673005 Kerala, India
}

\author{
K. J. Abraham AND C. L. LiBini
}

Central Marine Fisheries Research Institute-Department of Ocean Development Black-lip Pearl Oyster Project, PB 104, Marine Hill, Port Blair 744101 Andaman Nicobar Islands, India

\section{T. S. VELAYUDHAN}

Research Center of Central Marine Fisheries Research Institute, South Beach Road (Near Roche Park), Tuticorin 628001 Tamil Nadu, India

\author{
P. Radhakrishnan, K. S. Mohamed ${ }^{1}$, and M. J. Modayil \\ Central Marine Fisheries Research Institute, PO Box 1603, \\ Cochin 682018 Kerala, India
}

The black-lipped pearl oyster, Pinctada margaritifera, is sporadically distributed in the Indo-Pacific region, where they have been traditionally used for food, ornaments, jewelry, tools, and more recently for the production of black pearls (Lane et al. 2003). During the past two decades, black pearl farming programs have been initiated by several nations and are now at various levels of production, either at preliminary experimental stage or as a commercial industry (Friedman and Southgate 1999; Landman et al. 2001). The winged pearl oyster, Pteria penguin, also known as the mabe oyster, is commercially important and is used mainly for the production of mabe pearls (Haws 2002).

Mabes are assembled pearls produced by pasting hemispherical nuclei or plastic images on the inner surface of the shell of a host pearl oyster. Mabes are not as valuable as round pearls; however, they are easier to produce. One of the first records of cultured image pearls is the production of mother-of-pearl (MOP) Buddha figures from freshwater mussels by Buddhist monks in the 12th century (George

\footnotetext{
${ }^{1}$ Corresponding author.
}

1966). In the 19th century, a similar technique was developed in Japan to produce half pearls from marine pearl oysters (Shirai 1981). Half pearls produced from Pt. penguin are traditionally known as "mabe." However, the term mabe is now used generically to half pearls produced from a number of species of bivalves. Mabe pearls are produced in Japan, Indonesia, French Polynesia, Thailand, Mexico, Tonga, and Australia. The principal mabe-producing molluscs are the classic mabe pearl oyster, Pt. penguin, as well as Pteria sterna, Pinctada mazantlantica, Pinctada maxima, and P. margaritifera (Landman et al. 2001). In China, commercial ventures in mabe pearl production in Pt. penguin are performed profitably by two companies in Hainan Island and Leizhou Peninsula (Yu and Wang 2003); however, no detailed information is available. Ruiz-Rubio et al. (2006) have indicated the potential to develop a mabe pearl industry in Mexico based on Pt. sterna. In black pearl farms, mabe pearl production is considered as an additional source of income because the technique of mabe implantation is easy and can be performed by the farmers themselves without hiring a qualified technician (Haws 2002). The added advantage is that even defective 
or old oysters rejected by grafters for round pearl production can be used. Generally, nuclei of different shapes like hemispherical, teardrop, or dome shaped made of plastic are used, and the implantation is performed when the oysters gape naturally (Haws 2002) or by using anesthetic chemicals (Ruiz-Rubio et al. 2006). Efforts are also made to improve the quality of mabe pearl production through specific studies on the use of anesthetics, optimal implantation sites, and duration of culture period (Ruiz-Rubio et al. 2006). In India, mabe pearls of religious symbols have been produced in the Indian pearl oyster, Pinctada fucata (Mohamed et al. 2005), and the method of implantation, duration, and general husbandry with Best Management Practice has been elucidated.

Powdered menthol crystals have been used for relaxing $P$. maxima (Tranter 1957), P. fucata (Alagarswami 1991), and P. margaritifera (Norton et al. 1996). After testing the efficiency of 13 chemicals, Norton et al. (1996) have inferred that propylene phenoxetol, 2-phenoxyethanol, menthol crystals, menthol liquid, clove oil, and benzocaine can be used as relaxants for pearl oysters at specific dosages.

The black-lipped pearl oyster and the winged, or mabe, oyster of the family Pteridae are found in the coralline reef flats and on the pillars of wharfs of Andaman and Nicobar Islands in the Bay of Bengal, India (Alagarswami 1983). The island has a flourishing shellcraft industry using the nacreous shell (MOP) of these two oysters and a diverse group of gastropods and bivalves. Therefore, it was felt that there was considerable scope for developing a mabe pearl industry in Andaman and Nicobar Islands. This indicated the need to develop a regime for mabe production in these two species under tropical conditions. The main aim of the present research study was to develop a designer mabe pearl production technology suitable for $P$. margaritifera and Pt. penguin. To achieve this objective, experiments were carried out to (1) standardize the dosage of relaxants for P. margaritifera and Pt.penguin, (2) test the effectiveness of different adhesives for pasting the images, and (3) test the efficiency of crafted and shell-cut images for production of designer mabes.

\section{Materials and Methods}

The study was conducted using oysters collected from the natural beds, and the implanted oysters were reared in an experimental black pearl farm at Havelock Island in Andaman and Nicobar Islands. The pearl farm consisted of a wooden raft of $5 \times 5 \mathrm{~m}$ moored at a depth of $12 \mathrm{~m}$, and the experimental oysters were hung at a depth of 5-6 $\mathrm{m}$ from the sea surface in square lantern cages $(40 \times 40 \times 60 \mathrm{~cm})$ with a mesh of $10 \mathrm{~mm}$. The oysters collected from reef flats in the Islands were stocked in the pearl farm and reared for 3 mo prior to the experiments to stabilize the rearing conditions. For the experiments, the oysters were removed from the farm, cleaned, and were measured. Oysters with sufficient nacreous shell space on the inner side of the shell valve for mabe implantation were selected for the study. The dorso-ventral shell height (dorso-ventral measurement [DVM]) and shell thickness (Gervis and Sims 1992) were measured using digital calipers to the nearest $0.1 \mathrm{~mm}$, and the total weight was measured using a battery-operated digital balance to the nearest $0.1 \mathrm{~g}$.

\section{Standardizing the Dosage for Anesthetization}

For the present experiment, menthol crystals and clove oil were selected because of their easy availability and their efficiency as relaxants were tested. A screening test was conducted with $250 \mathrm{ppm}$ of menthol and $1.5 \mathrm{~mL} / \mathrm{L}$ clove oil (Norton et al. 1996), and the response of oysters was observed. Exposure to clove oil at the above concentration and at higher concentrations like 2 and $3 \mathrm{~mL} / \mathrm{L}$ did not relax the oysters. Hence, this was not used for further studies. The 250-ppm menthol treatment showed wide variations, with small oysters relaxing fast and larger oysters taking more time. At $250 \mathrm{ppm}$, the winged oysters relaxed very fast irrespective of size, and $40 \%$ mortality was observed on subsequent rearing. Therefore, P. margaritifera were grouped into large and small oysters based on shell measurements. P. margaritifera of DVM $101.0 \pm 10.3 \mathrm{~mm}$ and total weight $127.8 \pm 38.4 \mathrm{~g}$ were considered as large (PmL), and oysters of DVM $72.1 \pm 5.8 \mathrm{~mm}$ 
and total weight $70.1 \pm 24.2 \mathrm{~g}$ were grouped as small oysters $(\mathrm{PmS})$. Because size was not related to dosage in Pt. penguin $(\mathrm{Pt})$, oysters of DVM $96.5 \pm 17.9 \mathrm{~mm}$ and total weight $49.7 \pm 19.8 \mathrm{~g}$ were used for the experiments. Eighteen oysters each of PmL and PmS and nine of Pt were used for the experiments.

Powdered menthol crystals were dissolved in seawater, and the PmS were exposed to $250 \mathrm{ppm}$ because they relaxed easily in the screening test conducted earlier. The PmL were treated with higher doses, viz. 375 and 500 ppm menthol because their response was negligible at $250 \mathrm{ppm}$. Lower dosage of $145 \mathrm{ppm}$ was used for winged oysters because $250 \mathrm{ppm}$ was too strong for Pt. The stocking density was maintained at the rate of one oyster in $1 \mathrm{~L}$ of clean filtered seawater, and a control was placed for each treatment without menthol. The time taken for the oysters to be fully relaxed as indicated by the complete gaping of the valves and nonresponse to tactile stimuli was noted for each size group. When the oysters were found to be fully relaxed, they were kept back in troughs containing fresh filtered seawater. The time taken by the oysters to recover from the anesthetic effect was noted. The oysters were considered as fully recovered when they closed the valves naturally and resumed normal pumping activity. After observation in the laboratory for $6 \mathrm{~h}$, the oysters were stocked in the pearl farm in separate tagged lantern cages, and their survival was checked after 2, 3, 7, 14, 21, and $28 \mathrm{~d}$.

\section{Crafted Designer Image Preparation}

Two types of crafted designer images (image on which the pearly nacre coating has to be obtained) were used, those prepared from shell powder and images cut from molluscan shell. The former-type designer base images are made using specially fabricated metallic dies of required designs (Mohamed et al. 2005). For the preparation of the images, molluscan shell powder, the main ingredient, was sieved through a fine mesh sieve and mixed with a resin glue to form uniform semi-hard dough without clumps. With the help of a special handpress, the dough in the form of small pellet is pressed into the die to make a fine impression of the image on the dough. This was later trimmed to the appropriate dimension and shape and kept for hardening. The mold was further trimmed and shaped with the help of a carborundum grinder. These images are stored in a cool and dry place until use. The second type of images used were those cut from gastropod shells by craftsmen in the island, and the size of the images used ranged from 8 to $12 \mathrm{~mm}^{2}$.

\section{Efficiency of Commercial Adhesives in Image Fixation}

Three different adhesives, namely arsenicfree zinc oxide, polycarboxylate cement, and cyanoacrylate-based commercial glue (Fevikwik $^{\mathrm{TM}}$; Pidilite Industries, Mumbai, India) were used for mabe implantation. The efficiency was assessed based on rejection rates of implanted base images and survival of the oysters. Immediate rejections, if any, were observed in the laboratory for up to $6 \mathrm{~h}$ after implantation, and the oysters which retained the images were stocked in tagged cages with catch bags to collect images rejected by the oyster. The tagged cages were checked for rejects on $2,3,7$, and $14 \mathrm{~d}$ after implantation.

\section{Image Implantation}

The results of the above two experiments on the dosage of relaxant and on the type of glue to be used were applied for developing the protocol for the production of designer mabe. By this, the probable influence of relaxant usage and glue on survival of the oysters was eliminated. Prior to image implantation, the pearl oysters were relaxed using the specific dosage of menthol as described above. The oysters were held with the ventral side facing the implanter, and then, the mantle was lightly moved to the dorsal side. Traces of water and mantle fluid on the inner surface of the shell were wiped using clean sterilized paper towels cut into small pieces. Then, one or two drops of cyanoacrylatebased glue (Fevikwik) were applied on to the cleaned and dried spot, and the image was lightly pressed on this. The images were glued on either the left or the right valve in such a way that it allowed the oyster to completely close the valve without restriction. Care was 
taken to avoid damage to mantle by overflowing of the glue. After implantation, the oysters were placed back into clean filtered seawater for 2 $3 \mathrm{~h}$. Insertion of the image beneath the mantle (without gluing) through the pallial muscles to sites near the hinge (mantle cavity insertion [MCI]) as performed for P. fucata was carried out as per Mohamed et al. (2005). The oysters were stocked in tagged square lantern cages with nylon catch bags at one oyster per cage and hung from rafts. The pearl oyster cages were routinely cleaned of foulers and checked for mortality and rejection of images.

\section{Results}

In all the treatments, the oysters did not relax concurrently; rather, the relaxation was spaced. Large $P$. margaritifera started gaping by 60 $\mathrm{min}$, and by $120 \mathrm{~min}$, all the experimental oysters were completely anesthetized (Fig. 1). The smaller oysters responded well to $250 \mathrm{ppm}$ of menthol. The effect began in $30 \mathrm{~min}$, and nearly $92 \%$ of the oysters gaped in $95 \mathrm{~min}$. At $500 \mathrm{ppm}$, the oysters responded very fast, but the survival was below $50 \%$. Hence, this dosage was not considered for mabe implantation protocol. Pt. penguin oysters started gaping in $15 \mathrm{~min}$ but closed the valves on stimulation. In $60 \mathrm{~min}, 50 \%$ of the oysters had relaxed, and by $75 \mathrm{~min}$, all the oysters relaxed and had their valves open. When completely relaxed, the mantles of the oysters were found to collapse, but this did not affect the survival. The recovery from the anesthetic effect after implantation was within 15 min for all the oysters in all the treatments except for $500 \mathrm{ppm}$ for PmL. The survival during $28 \mathrm{~d}$ was $100 \%$, indicating that these dosages did not have any lethal effect.

Based on these experiments, it was inferred that large $P$. margaritifera can be completely anesthetized by $375 \mathrm{ppm}$ menthol within 120 min and small oysters by $250 \mathrm{ppm}$ within 95 min. Pt. penguin can be fully anaesthetized by $145 \mathrm{ppm}$ of menthol within $75 \mathrm{~min}$. It is better to complete the mabe implantation process within $15 \mathrm{~min}$ of anesthetization.

The gluing efficiency varied, and glues with zinc oxide as a component could not retain the image, whereas those containing polycarboxylate cement and Fevikwik with cyanoacrylate gave good results ( $>80 \%$ retention). The setting time ranged between 10 and $30 \mathrm{sec}$ and there was no damage to the mantle and other internal organs of the implanted oysters. However, Fevikwik is preferred because of its easy availability in the market and ease of application. Survival was $100 \%$ in all the trials.

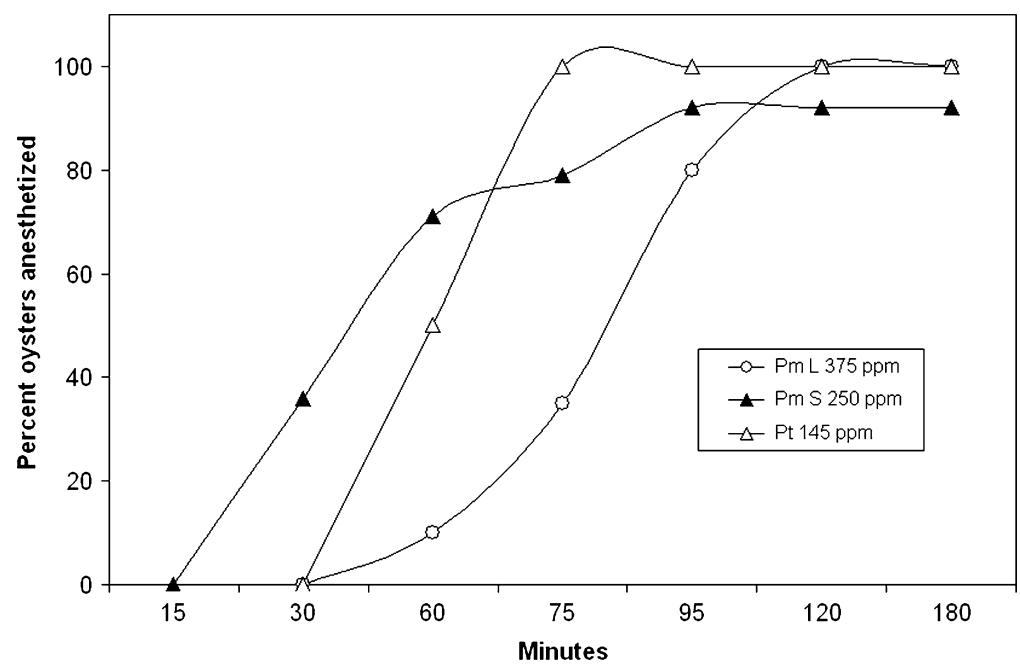

FIGURE 1. Time taken for Pinctada margaritifera and Pteria penguin for complete anesthetization after being administered selected dosages of menthol. 
For P. margaritifera, six different locations on the nacreous layer, viz. one to four on the ventral side of both left and right valves, were identified as ideal for gluing and two (Positions 5 and 6) near the posterior-dorsal side of the left valve were identified as ideal for MCI (Fig. 2). For Pt. penguin, three positions on the ventral side were identified as ideal for gluing (Fig. 2). Distorted mabes were formed when excess glue spilled out to the sides of the base image and when the base images were close to the nonnacreous layer.

The first check of nacre coating on mabes was performed in $60 \mathrm{~d}$, and it was observed that the nacre coating was uniform with good luster. When the mabes were retained for $101 \mathrm{~d}$, the nacre coating although good was thick, which reduced the clarity of the designer image. The sharpness of the contour in the image was abridged, and the whole image looked like a dome. Hence, in subsequent trials, the duration was reduced and good designer mabes were harvested in 60-70 d. Both the methods tried for placing the base image gave good results, with $50 \%$ retention in MCI technique and $100 \%$ in gluing. The quality as assessed by subjective attributes like color and luster indicated that the nacre coating on both types of images, viz. assembled image and shell-cut image, were good. Shell-cut images have more sharpness compared to the former type, but the latter has a better three-dimensional effect.
Considerable variation was seen in color of mabe based on the location in the shell. In P. margaritifera, images placed near the mantle edge (Positions 1-4) were grayish brown with graded rainbow overtones, while those placed at Positions 5 and 6 were uniformly pearly white. The mabe produced from Pt. penguin was coppery brown with rainbow hues.

\section{Discussion}

In the present study, dosage of menthol for anesthetizing the black-lipped pearl oyster and mabe oysters of a specific size group was standardized. Unlike the observations of Norton et al. (1996), in the present study, variations were observed in relaxation time of different size group of the oysters and between species. One reason may be that the temperature was slightly higher, ranging between 26 and $28 \mathrm{C}$ and the black-lipped pearl oysters used were also smaller. Considerable variations in response to relaxants between species of molluscs have been reported (Rumham et al. 1965; Haesman et al. 1995; Acosta-Salmon and Davis 2007). Minor differences were also observed in the behavior of the oysters. Norton et al. (1996) have reported that the oysters upon relaxation extended their foot, but such behavior was not observed in the present study. Mantle collapse was observed, but this did not affect the survival. Norton et al. (1996) have considered the probable reason for this as the reduction in
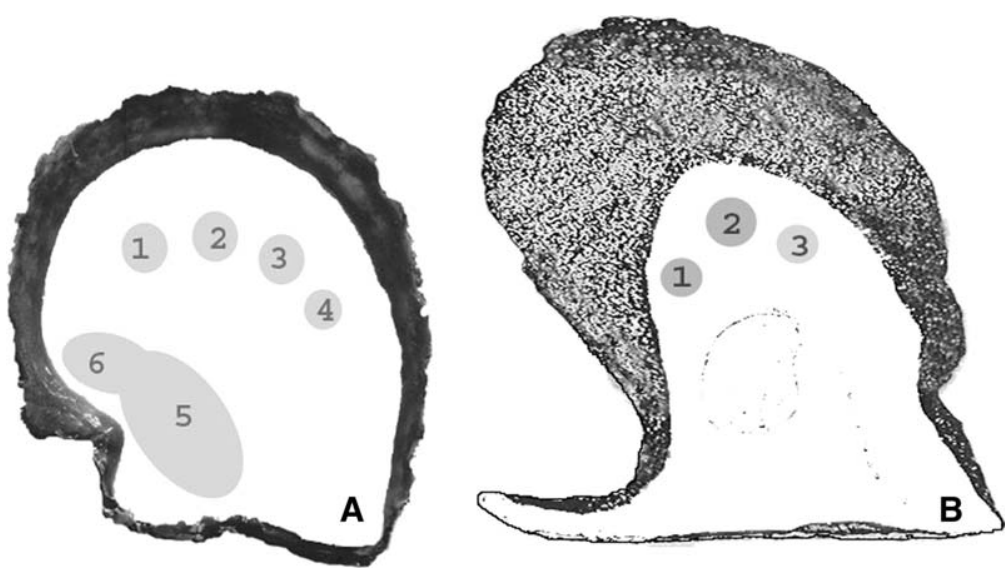

FIGURE 2. Positions suitable for mabe production on the right valve in (A) Pinctada margaritifera and (B) Pteria penguin. 
hemolymph pressure. Relaxing the oysters had several advantages; this gave better exposure of the implantation site (nacreous layer), spacing of the mabes was more accurate, and it also helped to apply the glue accurately without spilling over and damaging the mantle and internal tissues. Forcefully opening the oysters without relaxing the oysters can damage the adductor muscle because of overstretching and lead to mortality of the oysters (Norton et al. 1996).

Gluing was found to be more effective with higher production efficiency because in MCI, only one designer mabe can be produced. Moreover, one to five mabes can be produced from one oyster using this technique by judiciously spacing the right-size images in the upper and lower valves avoiding the non-nacreous part and area surrounding the adductor muscle. Possibility of multiple mabe implantations in Pt. sterna has been indicated (Saucedo et al. 1998). Ruiz-Rubio et al. (2006) found position of pasting the image on the shell to affect the quality of the round-, oval-, or drop-shaped mabes in Pt. sterna. They obtained better symmetrical mabes from the right valve, and the mabes on the left valve were affected by the growth of the adductor muscle because the grow-out period was higher and the possibility of mantle not being able to cover the nuclei after implantation because of increase in shell surface was also implicated. However, in the present study, such asymmetrical nacre deposition was not found and the possibility of adductor muscle growing over the mabe was not encountered probably because of the short duration of the culture period. Uniform coating of attractive and lustrous nacre on the crafted and cut images indicates the scope to produce diverse and personalized made-to-order designer mabes. This study indicated that smaller oysters can be used for mabe pearl production and that according to the size of the host oyster, the crafted image must be made smaller.

Comparatively longer gestation period is required for mabe pearl production in other locations (Landman et al. 2001). While producing half-round mabe pearls in Pt. sterna, RuizRubio et al. (2006) found that commercial nacre thickness is reached in $5 \mathrm{mo}$, but commercial quality is highest after 9 mo of implanting. In the present study, it was observed that culturing the implanted oysters for longer period reduced the sharpness of image pearls. This cut short the grow-out period to $2 \mathrm{mo}$. What effect this will have on the durability of the designer mabes has not been determined; however, for $P$. fucata 60-d duration of coating gives more than $3 \mathrm{yr}$ of life to the mabes (Mohamed et al. 2005).

Usually after harvest, the pearl oyster is sacrificed and the resultant mabe pearl is converted to a curio by mounting it on decorative stand or into jewelry by converting it to pendants, brooches, or rings using gold or silver. The mabe can also be cut from the shell to be processed. The base image is removed, the blister is filled with resin, and a backing disc made of nacre is attached to make a complete mabe pearl (Matlins 1996; Landman et al. 2001). In international markets, such mabe pearls of $10-20 \mathrm{~mm}^{2}$ are priced between \$US100 and \$US350 (Matlins 1996). The presently developed designer mabes can also be converted in the above manner.

This study indicates the potential for development of a designer mabe pearl production industry. The technique is simple and can be learned very easily by novices. Moreover, the production period is less than 3 mo. In the Andaman and Nicobar Islands, it is possible that this technology can also be used as an alternate source of livelihood for the tsunami-affected villagers by developing their skill in preparing designercrafted base images. The market for mabes can be developed within the island itself taking advantage of the increasing number of domestic and international tourists visiting the island each year. The island has also highly skilled shell craftsmen who can very deftly convert the shell with mabe into an exquisite piece of art. In case large oysters are used as hosts, the remaining shell after taking out the mabe need not be wasted; instead, it can be used for making small trinkets, the technique for which already exists in the island.

\section{Acknowledgments}

Authors are grateful to the Department of Ocean Development, Government of India, for the financial support to the project. They are also 
thankful to the Department of Fisheries, Andaman and Nicobar Islands, for logistic support.

\section{Literature Cited}

Acosta-Salmon, H. and M. Davis. 2007. Inducing relaxation in the queen conch Strombus gigas (L.) for cultured pearl production. Aquaculture 262:73-77.

Alagarswami, K. 1983. Mariculture potential of the Andaman and Nicobar Islands. Bulletin of the Central Marine Fisheries Research Institute 34:72-78.

Alagarswami, K. 1991. Production of cultured pearls. Indian Council of Agricultural Research, New Delhi, India.

Friedman, K. J. and P. C. Southgate. 1999. Grow-out of black-lipped pearl oysters, Pinctada margaritifera, on chaplets in suspended culture in Solomon Islands. Journal of Shellfish Research 18:451-458.

George, C. D. 1966. The cultured pearl, its history and development to the present day. Australian Gemmologist 8:10-26.

Gervis, M. H. and N. A. Sims. 1992. The biology and culture of pearl oysters (Bivalvia: Pteridae) ICLARM Studies and Reviews. ICLARM, Manila, Philippines.

Haesman, M. P., W. A. O'Connor, and A. W. J. Frazer. 1995. Induction of anesthesia in the commercial scallop Pecten fumatus Reeve. Aquaculture 131:231-238.

Haws, M. 2002. The basic methods of pearl farming: a layman's manual. Publication 17, Center for Tropical and Subtropical Aquaculture, Hawaii, USA.

Landman, N. H., P. M. Mikkelsen, R. Bieler, and B. Bronson. 2001. Pearls: a natural history. Harry and Abrams, Inc., New York, New York, USA.
Lane, I., O. Oengpepa, and J. Bell. 2003. Production and grow-out of the black-lipped pearl oyster Pinctada margaritifera. Aquaculture Asia 8:5-7.

Matlins, A. L. 1996. The pearl book: the definitive buying guide. Gemstone Press, Woodstock, Vermont, USA.

Mohamed, K. S., V. Kripa, P. Radhakrishnan, P. S. Alloycious, R. Leena, K. P. S. Koya, and K. K. Appukuttan. 2005. Mabe pearls: a simple way to value added pearls (Brochure). Central Marine Fisheries Research Institute, Cochin, India.

Norton, J. H., M. Dashorst, T. M. Lansky, and R. J. Mayer. 1996. An evaluation of some relaxants for use with pearl oysters. Aquaculture 144:39-52.

Ruiz-Rubio, H., H. Acosta-Salmón, A. Olivera, P. C. Southgate, and C. Rangel-Dávalos. 2006. The influence of culture method and culture period on quality of half-pearls (mabe) from the winged pearl oyster Pteria sterna, Gould, 1851. Aquaculture 254:269-274.

Rumham, N. W., K. Isarankura, and B. J. Smith. 1965. Methods for narcotizing and anaesthetizing gastropods. Malacologia 2:231-238.

Saucedo, P., M. Monteforte, and F. Blanc. 1998. Changes in shell dimensions of pearl oysters, Pinctada mazatlantica (Hanley 1856) and Pteria sterna (Gould, 1851), during growth as criteria for mabe pearl implants. Aquaculture Research 29:801-814.

Shirai, S. 1981. Pearls. Shunposha Photo printing Co., Ltd., Yamaguchi, Japan.

Tranter, D. J. 1957. Pearl culture in Australia. Australian Journal of Science 19:230-232.

Yu, X. and M. Wang. 2003. The farming of and cultivating of wing oyster Pteria penguin in Southern China. Secretariat of the Pacific Community, Pearl Oyster Information Bulletin 16, Noumea, New Caledonia. 